\title{
Bronchial and alveolar components of exhaled nitric oxide and their relationship
}

\section{To the Editors:}

Considerable confusion exists about the clinical use of exhaled nitric oxide measurement in general, and its bronchial and alveolar contributions in particular, for instance in response to treatment. An additional effect needs to be factored in when considering the degree of alveolar nitric oxide abnormality and its response to therapeutic interventions that may or may not be targeted to the lung periphery. Indeed, the alveolar nitric oxide value computed from exhaled nitric oxide measurement at multiple flows with the so-called slope-intercept method [1, 2] can overestimate the true nitric oxide produced by inflammation in the alveolar air spaces. Such overestimation arises when the bronchial nitric oxide back-diffuses into the alveolar air space and thus contaminates the alveolar nitric oxide measurement with nitric oxide that originates from the more proximal airways. Two correction formulas have been published independently [3, 4] proposing to estimate true alveolar nitric oxide by subtracting from the measured alveolar nitric oxide a bronchial nitric oxidedependent portion corresponding to back-diffusion. However, it has also been shown that airway constriction of peripheral conductive airways may at least partly impair back-diffusion [5]. Thus, in the case of peripheral lung disease, the application of correction formulas that assume unimpaired back-diffusion can erroneously lead to overcorrection and, ultimately, to negative alveolar nitric oxide values. The problem with the real lung is that it is difficult to judge whether and to what extent back-diffusion is impaired, although independent measures of small airway constriction could be envisioned in an attempt to determine this. In the meantime, we advocate here a more pragmatic approach.

One way to inspect uncorrected alveolar nitric oxide concentration $(\mathrm{CA}, \mathrm{NO})$ for true abnormality is by first plotting it against maximal bronchial nitric oxide production $\left(J^{\prime}\right.$ aw,NO) as in figure 1a for data retrieved from 30 publications reporting both alveolar nitric oxide and bronchial nitric oxide production in asthma patients; if available from these asthma studies, data on normal control subjects were also retrieved (table 1). Each data point in figure 1a represents the uncorrected values of $J^{\prime}$ aw, NO and $\mathrm{CA}, \mathrm{NO}$ corresponding to any given group of asthma patients or normal subjects retrieved from each study. In those papers where exhaled nitric oxide fraction at $50 \mathrm{~mL} \cdot \mathrm{s}^{-1}(F \mathrm{eNO}, 0.05)$ was reported instead of $J^{\prime}$ aw, NO, the latter was computed using the average multiplicative factor between $J^{\prime}$ aw,NO and FeNO,0.05 obtained from 15 out of the 30 papers where both were reported (mean \pm SD factor $45 \pm 4$ ). From figure $1 \mathrm{a}$, we can now assess each ( ${ }^{\prime}$ aw,NO, CA,NO) data point with respect to a previously established "zone of normality" (dashed lines), which delimits combinations of $\mathrm{CA}, \mathrm{NO}$ and $J^{\prime}$ aw,NO for which true alveolar nitric oxide is in fact normal, and any elevated $\mathrm{CA}_{\mathrm{A}, \mathrm{NO}}$ value can be attributed entirely to the increased $J$ 'aw,NO when full backdiffusion applies [4]. The 95\% confidence interval around the

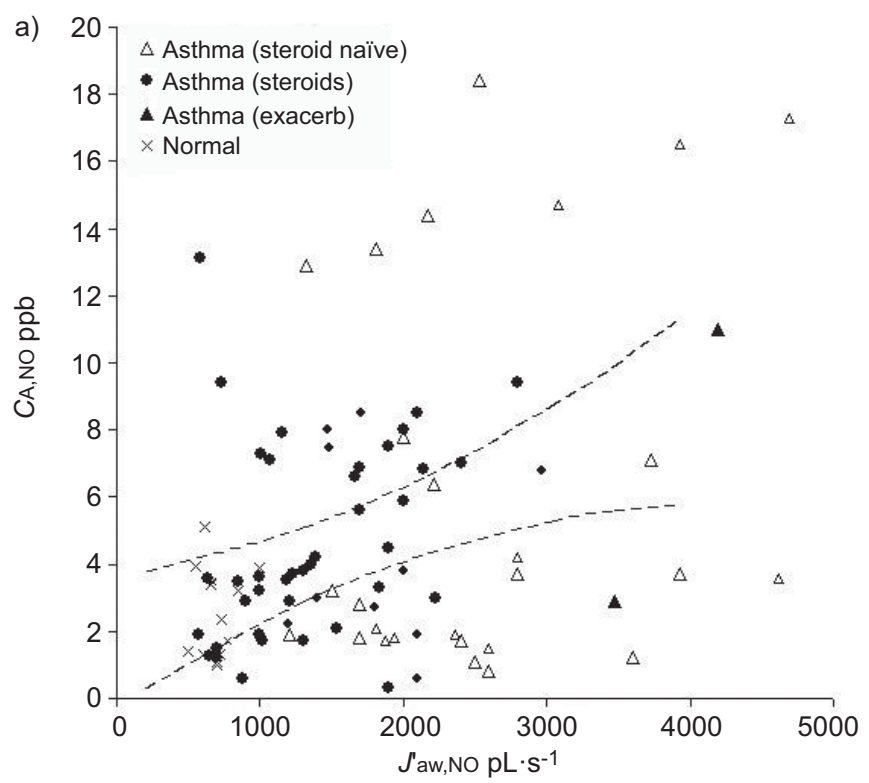

b)

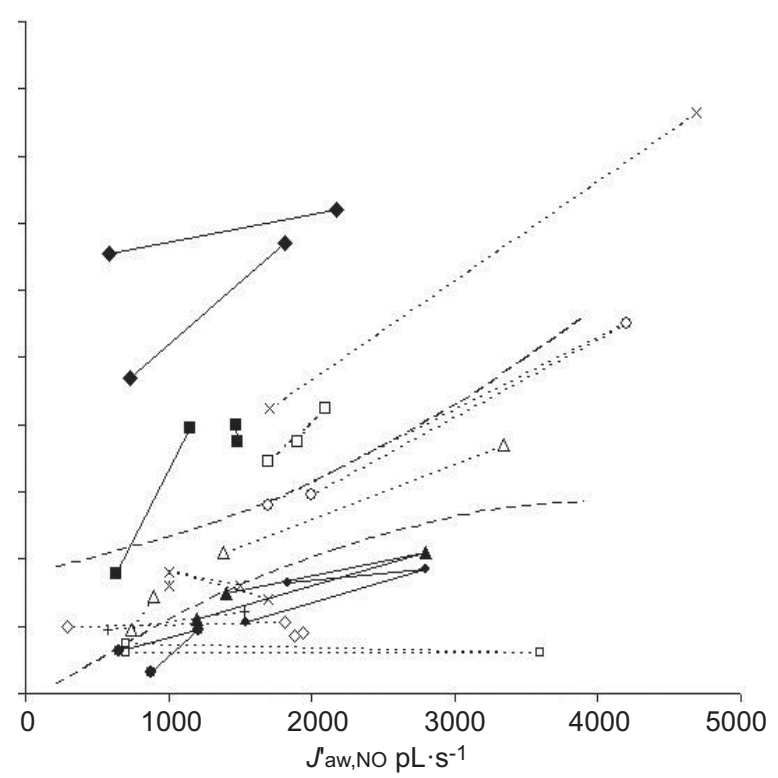

FIGURE 1. a) Uncorrected values of alveolar nitric oxide concentration (CA,NO) plotted as a function of bronchial nitric oxide production ( $J$ 'aw,NO) obtained from all studies listed in table 1. Data points corresponding to the average value of $\leqslant 10$ subjects are depicted by a slightly smaller symbol. Dashed lines, delimiting the zone of normalcy, indicate the $95 \%$ confidence interval around the regression line previously obtained from experimental data on normal subjects and stable asthma patients [4]. b) Uncorrected values of CA,NO plotted as a function of $J^{\prime}$ aw,NO obtained from interventional asthma studies see table 1 [6-19]; solid lines refer to a subset of interventional studies comparing two treatment arms see table 1 [6-10]. In this panel, different symbol types and sizes are used to identify data originating from different papers. Dashed lines: zone of normality (same representation as in (a)). 


\begin{tabular}{|c|c|}
\hline TABLE 1 & $\begin{array}{l}\text { Publication sources from which alveolar nitric } \\
\text { oxide concentration and maximal bronchial nitric } \\
\text { oxide production values are retrieved and } \\
\text { corresponding subject groups under study }\end{array}$ \\
\hline First author [ref.] & Subject groups under study \\
\hline BERRY [6] & Asthma/steroids versus normal subjects \\
\hline FRITSCHER [7] & Asthma/steroids and steroid naïve \\
\hline KanAZAWA [8] & Asthma/steroids and steroid naïve \\
\hline Nicolini [9] & Asthma/steroids and steroid naïve \\
\hline WiLLIAMSON [10] & Asthma/steroids and steroid naïve \\
\hline BRINDICCI [11] & Asthma/steroid naïve versus normal subjects \\
\hline Cohen [12] & Asthma/steroids and steroid naïve \\
\hline GeLB [13] & $\begin{array}{c}\text { Asthma/steroids and steroid naïve versus } \\
\text { normal subjects }\end{array}$ \\
\hline GeLB [14] & Asthma/steroids \\
\hline GeLB [15] & $\begin{array}{c}\text { Asthma/steroids and exacerbation versus } \\
\text { normal subjects }\end{array}$ \\
\hline LEHTIMÄKI [16] & $\begin{array}{l}\text { Asthma/steroids and steroid naïve versus } \\
\text { normal subjects }\end{array}$ \\
\hline LEHTIMÄKI [17] & $\begin{array}{l}\text { Asthma/steroids and steroid naiive versus } \\
\text { normal subjects }\end{array}$ \\
\hline SPEARS [18] & Asthma/steroids \\
\hline VAN MuYLEM [19] & Asthma/steroids and steroid naïve \\
\hline WILLIAMSON [20] & Asthma/steroids \\
\hline BRINDICCI [21] & $\begin{array}{l}\text { Asthma/steroids and steroid naive and } \\
\text { exacerbations versus normal subjects }\end{array}$ \\
\hline Delclaux [22] & Asthma/steroids versus normal subjects \\
\hline GeLB [23] & $\begin{array}{c}\text { Asthma/steroids and steroid naïve versus } \\
\text { normal subjects }\end{array}$ \\
\hline GeLB [24] & Asthma/steroids \\
\hline KeRCKX [25] & Asthma/steroids versus normal subjects \\
\hline КовAYASHI [26] & Asthma/steroid naïve versus normal subjects \\
\hline LEHTIMÄKI [27] & Asthma/steroid naïve versus normal subjects \\
\hline LEHTIMÄKI [28] & Asthma/steroid naïve versus normal subjects \\
\hline LEHTIMÄKI [29] & Asthma/steroid naïve versus normal subjects \\
\hline МАнUт [30] & Asthma/steroids \\
\hline МАTSUMOTO [31] & Asthma/steroids \\
\hline NiHLberg [32] & Asthma/steroid naïve versus normal subjects \\
\hline Van Veen [33] & Asthma/steroids \\
\hline VERBANCK [34] & Asthma/steroids versus normal subjects \\
\hline WILLIAMSON [35] & Asthma/steroids versus normal subjects \\
\hline
\end{tabular}

This reference list is limited to those papers where steroid use in asthma study groups or subgroups could be clearly identified.

regression line was previously obtained from experimental data on normal subjects and stable asthma patients [4]. Importantly, the experimental regression line itself (not represented here for clarity) corresponding to an average 1.7-ppb increase in CA,NO for every $1,000 \mathrm{pL} \cdot \mathrm{s}^{-1}$ increase in $J^{\prime}$ aw, NO, was almost indistinguishable from that predicted by simulations of convective and diffusive gas transport in a lung model with normal peripheral airways [4].

It can be seen from figure 1a that, despite methodological differences and anthropometric variability in geographical regions from which the different research papers originate, almost all normal data fell within the zone of normality, and more specifically in the lower range of both $J^{\prime}$ aw, NO $\left(<1,200 \mathrm{pL} \cdot \mathrm{s}^{-1}\right)$ and $\mathrm{CA}, \mathrm{NO}(<5 \mathrm{ppb})$. At the other end of the spectrum $\left(J^{\prime} \mathrm{aw}, \mathrm{NO}\right.$ $>2,000 \mathrm{pL} \cdot \mathrm{s}^{-1}$ and outside the zone of normality), we mostly observed data points for groups of asthma patients who were either steroid-naïve (open triangles) or in exacerbation (closed triangles). Two subsets of asthma patients warrant particular attention. On one hand, the patient groups with combinations of $J^{\prime}$ aw,NO and CA,NO located above the zone of normality are patients with a true increase of nitric oxide originating in the alveolar spaces, i.e. an alveolar nitric oxide in excess of what could be expected on basis of their corresponding bronchial nitric oxide production, even in case of full back-diffusion. In these patients, CA,NO values following a full back-diffusion correction would still be abnormal. On the other hand, patient groups with combinations of $J^{\prime}$ aw,NO and $\mathrm{CA}, \mathrm{NO}$ below the zone of normality corresponded to patients for whom back-diffusion is hampered by considerable airway constriction, in which case back-diffusion correction would lead to negative alveolar nitric oxide values [19].

Once abnormality of the uncorrected $\mathrm{CA}, \mathrm{NO}$ is established based on a $J^{\prime} \mathrm{aw}, \mathrm{NO} / \mathrm{CA}, \mathrm{NO}$ plot, the same representation can also help interpret response to treatment. Figure $1 \mathrm{~b}$ shows data from 15 interventional studies in asthma patients [6-21] including five studies (solid symbols and lines) where two treatment arms were compared, either within the same group of asthma patients or between two comparable patient groups [6-11]. It can be seen that the majority of studies follows the "normal" CA,NO decrease with respect to $J^{\prime} \mathrm{aw}, \mathrm{NO}$ decrease, in which case the treatment effectively lowers bronchial nitric oxide production but does not really affect alveolar nitric oxide when taking into account the back-diffusion effect. Some studies follow a steeper than normal CA,NO decrease with $J$ 'aw,NO decrease, indicating a true alveolar effect, while others show a marked $J^{\prime}$ aw,NO decrease with no concomitant $\mathrm{CA}, \mathrm{NO}$ decrease, usually in patients with pretreatment data points located below the zone of normality. In fact, it has been shown recently that after steroid treatment, such patients may even paradoxically increase their uncorrected CA,NO value, probably because impairment to back-diffusion is lifted [19]. Surely, some interlaboratory methodological issues could influence the absolute value of what constitutes a "normal" slope in the relationship between $\mathrm{CA}, \mathrm{NO}$ and J'aw,NO. However, when comparing slopes of $\mathrm{CA}, \mathrm{NO}$ versus $J^{\prime}$ aw,NO between different treatment arms studied in the same laboratory, a relatively steeper slope should signal a more peripheral effect. In fact, for the five comparative studies (solid lines in fig. 1b), the relatively steeper slope did correspond to the treatment arm with a intended more peripheral therapeutic effect.

In summary, we have taken the opportunity to consider some of the issues with exhaled nitric oxide measurement that have frequently frustrated researchers willing to incorporate this biomarker of inflammation in their study protocol. It would not be the first simple, noninvasive test that has been characterised by an initial outburst of enthusiasm, followed by sound scepticism or discouragement because its interpretation proves to be more complicated than the test itself, at which point it becomes at risk of being all but abandoned. With the comprehensive compilation and interpretation of published alveolar nitric oxide data in asthma to date, we have attempted to reinforce the interest in the exhaled nitric oxide test and, in particular, the components representing alveolar and bronchial nitric oxide. We propose that before readily applying a full back-diffusion correction, individual 
values of $\mathrm{CA}$,NO would be plotted versus their corresponding value of $J^{\prime}$ aw, NO, and assessed with respect to what has been previously obtained (fig. 1). Besides offering the possibility to diagnose possible equipment-related biases, such an approach could identify patients below the zone of normality for whom the full back-diffusion correction should not be applied. Finally, the proposed $J^{\prime}$ aw,NO/CA,NO data plots enable a direct comparison of different treatment interventions and identification of a more peripheral effect.

Sylvia Verbanck*, Andrei Malinovschi ${ }^{*}$, , Steven George ${ }^{+}$, Arthur F. Gelb ${ }^{\S f}$, Walter Vincken* and Alain Van Muylem** ${ }^{*}$ Respiratory Division, University Hospital, Vrije Universiteit Brussels, ${ }^{* *}$ Chest Dept, Cliniques Universitaires Erasme, Université Libre de Bruxelles, Brussels, Belgium. "Clinical Physiology, "Respiratory Medicine and Allergology, Dept of Medical Sciences, Uppsala University, Uppsala, Sweden. ${ }^{+}$Dept of Biomedical Engineering, University of California Irvine, Irvine, CA, ${ }^{\S}$ Pulmonary Division, Dept of Medicine, Lakewood Regional Medical Center, Lakewood, CA, and ${ }^{f}$ Geffen School of Medicine, UCLA Medical Center, Los Angeles, CA, USA.

Correspondence: S. Verbanck, Respiratory Division, University Hospital, Vrije Universiteit Brussels, Laarbeeklaan101, Brussels 1090, Belgium. E-mail: sylvia.verbanck@uzbrussel.be

Statement of Interest: None declared.

\section{REFERENCES}

1 Tsoukias NM, Tannous Z, Wilson AF, et al. Single-exhalation profiles of $\mathrm{NO}$ and $\mathrm{CO}_{2}$ in humans: effect of dynamically changing flow rate. J Appl Physiol 1998; 85: 642-652.

2 Pietropaoli AP, Perillo IB, Torres A, et al. Simultaneous measurement of nitric oxide production by conducting and alveolar airways of humans. J Appl Physiol, 87: 1532-1542.

3 Condorelli P, Shin HW, Aledia AS, et al. A simple technique to characterize proximal and peripheral nitric oxide exchange using constant flow exhalations and an axial diffusion model. J Appl Physiol 2007; 102: 417-425.

4 Kerckx Y, Michils A, Van Muylem A. Airway contribution to alveolar nitric oxide in healthy subjects and stable asthma patients. J Appl Physiol 2008; 104: 918-924.

5 Verbanck S, Kerckx Y, Schuermans D, et al. Effect of airways constriction on exhaled nitric oxide. J Appl Physiol 2008; 104: 925-930.

6 Berry M, Hargadon B, Morgan A, et al. Alveolar nitric oxide in adults with asthma: evidence of distal lung inflammation in refractory asthma. Eur Respir J 2005; 25: 986-991.

7 Fritscher LG, Rodrigues MT, Zamel N, et al. The effect of montelukast on exhaled nitric oxide of alveolar and bronchial origin in inhaled corticosteroid-treated asthma. Respir Med 2009; 103: 296-300.

8 Kanazawa H, Kyoh S, Asai K, et al. Validity of measurement of two specific biomarkers for the assessment of small airways inflammation in asthma. J Asthma 2010; 47: 400-406.

9 Nicolini G, Chetta A, Simonazzi A, et al. Both bronchial and alveolar exhaled nitric oxide are reduced with extrafine beclomethasone dipropionate in asthma. Allergy Asthma Proc 2010; 31: 85-90.

10 Williamson PA, Menzies D, Nair A, et al. A proof-of-concept study to evaluate the antiinflammatory effects of a novel soluble cyclodextrin formulation of nebulized budesonide in patients with mild to moderate asthma. Ann Allergy Asthma Immunol 2009; 102: 161-167.

11 Brindicci C, Ito K, Barnes PJ, et al. Effect of an inducible nitric oxide synthase inhibitor on differential flow-exhaled nitric oxide in asthmatic patients and healthy volunteers. Chest 2007; 132: 581-588.

12 Cohen J, Douma WR, ten Hacken NH, et al. Ciclesonide improves measures of small airway involvement in asthma. Eur Respir J 2008; 31: 1213-1220.

13 Gelb AF, Taylor CF, Shinar CM, et al. Effect of fluticasone $250 \mu \mathrm{g} /$ salmeterol $50 \mu \mathrm{g}$ and montelukast on exhaled nitric oxide in asthmatic patients. Can Respir J 2008; 15: 193-198.

14 Gelb AF, Taylor CF, Simmons M, et al. Role of add-on zileuton on total exhaled, large airway, and small airway/alveolar nitric oxide in moderate-severe persistent adult asthmatics on fluticasone $250 \mu \mathrm{g} /$ salmeterol $50 \mu \mathrm{g}$. Pulm Pharmacol Ther 2009; 22: 516-521.

15 Gelb AF, George SC, Silkoff PE, et al. Central and peripheral airway/alveolar sites of exhaled nitric oxide in acute asthma. Thorax 2010; 65: 619-625.

16 Lehtimäki L, Kankaanranta H, Saarelainen S, et al. Extended exhaled NO measurement differentiates between alveolar and bronchial inflammation. Am J Respir Crit Care Med 2001; 163: 1557-1561.

17 Lehtimäki L, Kankaanranta H, Saarelainen S, et al. Inhaled fluticasone decreases bronchial but not alveolar nitric oxide output in asthma. Eur Respir J 2001; 18: 635-639.

18 Spears M, Weir CJ, Smith AD, et al. Bronchial nitric oxide flux $\left(J^{\prime}\right.$ aw $)$ is sensitive to oral corticosteroids in smokers with asthma. Respir Med 2011; 105: 1823-1830.

19 Van Muylem A, Kerckx Y, Michils A. Acinar effect of inhaled steroids evidenced by exhaled nitric oxide. J Allergy Clin Immunol 2010; 126: 730-735.

20 Williamson PA, Clearie K, Vaidyanathan S, et al. Effects of methacholine challenge on alveolar nitric oxide. Thorax 2009; 64: 549-550.

21 Brindicci C, Ito K, Barnes PJ, et al. Differential flow analysis of exhaled nitric oxide in patients with asthma of differing severity. Chest 2007; 131: 1353-1362.

22 Delclaux C, Mahut B, Zerah-Lancner F, et al. Increased nitric oxide output from alveolar origin during liver cirrhosis versus bronchial source during asthma. Am J Respir Crit Care Med 2002; 165: 332-337.

23 Gelb AF, Taylor CF, Nussbaum E, et al. Alveolar and airway sites of nitric oxide inflammation in treated asthma. Am J Respir Crit Care Med 2004; 170: 737-741.

24 Gelb AF, Taylor CF, Shinar CM, et al. Role of spirometry and exhaled nitric oxide to predict exacerbations in treated asthmatics. Chest 2006; 129: 1492-1499.

25 Kerckx Y, Michils A, Van Muylem A. Airway contribution to alveolar nitric oxide in healthy subjects and stable asthma patients. J Appl Physiol 2008; 104: 918-924.

26 Kobayashi D, Tochino Y, Kanazawa H, et al. Comparison of alveolar nitric oxide concentrations using two different methods for assessing small airways obstruction in asthma. Respirology 2011; 16: 862-868.

27 Lehtimäki L, Turjanmaa V, Kankaanranta H, et al. Increased bronchial nitric oxide production in patients with asthma measured with a novel method of different exhalation flow rates. Ann Med 2000; 32: 417-423.

28 Lehtimäki L, Kankaanranta H, Saarelainen S, et al. Increased alveolar nitric oxide concentration in asthmatic patients with nocturnal symptoms. Eur Respir J 2002; 20: 841-845.

29 Lehtimäki L, Kankaanranta H, Saarelainen S, et al. Peripheral inflammation in patients with asthmatic symptoms but normal lung function. J Asthma 2005; 42: 605-609.

30 Mahut B, Trinquart L, Le Bourgeois M, et al. Multicentre trial evaluating alveolar NO fraction as a marker of asthma control and severity. Allergy 2010; 65: 636-644. 
31 Matsumoto H, Niimi A, Jinnai M, et al. Association of alveolar nitric oxide levels with pulmonary function and its reversibility in stable asthma. Respiration 2011; 81: 311-317.

32 Nihlberg K, Andersson-Sjöland A, Tufvesson E, et al. Altered matrix production in the distal airways of individuals with asthma. Thorax 2010; 65: 670-676.

33 Van Veen IH, Sterk PJ, Schot R, et al. Alveolar nitric oxide versus measures of peripheral airway dysfunction in severe asthma. Eur Respir J 2006; 27: 951-956.
34 Verbanck S, Schuermans D, Vincken W. Inflammation and airway function in the lung periphery of patients with stable asthma. J Allergy Clin Immunol 2010; 125: 611-616.

35 Williamson PA, Clearie K, Menzies D, et al. Assessment of smallairways disease using alveolar nitric oxide and impulse oscillometry in asthma and COPD. Lung 2011; 189: 121-129.

\section{Efficacy of nebulised liposomal amphotericin B in the attack and maintenance treatment of ABPA}

\section{To the Editors:}

Allergic bronchopulmonary aspergillosis (ABPA) is a pulmonary disorder that results from a hypersensitivity reaction to Aspergillus spp. It has been estimated to occur in 1-3\% of people with chronic asthma and $2-15 \%$ of those with cystic fibrosis [1]. The natural history of ABPA is characterised by exacerbations that can threaten the patient's survival and prognosis [1]. Repetition of such exacerbations is responsible for the development of bronchiectasis, permanent obstructive ventilation defect or fibrotic lung lesions. Prognosis mainly depends on the very early treatment of exacerbations before bronchiectasis sets in. In 2008, the guidelines of the Infectious Diseases Society of America advised combination therapy in ABPA [2]: systemic glucocorticoids to limit the inflammatory component and antifungals to limit mycelium proliferation. However, even though glucocorticoid therapy and antifungals are the treatment of choice for acutestage ABPA and exacerbations, there are no data to guide the duration of this treatment. Therefore, the current objectives for the management of ABPA are a decrease in the frequency and duration of exacerbations, and a limited solicitation of glucocorticoids. Consequently, the maintenance treatment in the management of ABPA remains a current and progressive problem for pneumologists.

We describe a case of ABPA that was difficult to control using the standard treatment regimen, but which improved dramatically and durably following administration of nebulised liposomal amphotericin B (LAmB).

In May 2010, a 67-yr-old female presented with fever and productive cough, with sputum plugs and a history of epilepsy treated with phenobarbital. In the preceding 3 months, she had presented recurrent chest infections resistant to amoxicillin and ciprofloxacin; glucocorticoids $\left(1 \mathrm{mg} \cdot \mathrm{kg}^{-1} \cdot \mathrm{day}^{-1}\right.$ prednisolone for 2 weeks) had been started without any clear improvement.

At that time, ABPA was suspected. A thoracic computed tomography (CT) scan showed right upper lobe consolidation with a bronchocele and the patient's absolute eosinophil count was 1,170 cells $\cdot \mu \mathrm{L}^{-1}$. Further investigations showed increased total immunoglobulin $(\mathrm{Ig}) \mathrm{E}\left(1,154 \mathrm{IU} \cdot \mathrm{mL}^{-1}\right)$ and specific antiAspergillus fumigatus IgE levels $\left(12.9 \mathrm{kU} \cdot \mathrm{L}^{-1}\right)$, and the presence of specific anti- $A$. fumigatus precipitins in the serum (four lines).
Corticosteroids were maintained for 2 weeks $\left(1 \mathrm{mg} \cdot \mathrm{kg}^{-1} \cdot \mathrm{day}^{-1}\right)$ after which the dose was reduced (5-mg decrease every 2 weeks) and itraconazole was added (200 $\mathrm{mg}$ b.i.d.).

After 4 weeks of treatment, the patient's clinical status deteriorated and new consolidations appeared on the CT scan (fig. 1a and $b$ ); due to phenobarbital interaction, plasma itraconazole concentration was very low, so itraconazole treatment was withdrawn. The patient was therefore treated with the following regimen: prednisolone $\left(0.5 \mathrm{mg} \cdot \mathrm{kg}^{-1} \cdot \mathrm{day}^{-1}\right.$ for 2 weeks, then reduced by 5 mg every 2 weeks until discontinuation), associated with nebulisations of LAmB ( $25 \mathrm{mg}$ twice weekly) until steroids were stopped, followed by a maintenance dose of LAmB (25 mg once weekly) to prevent subsequent ABPA exacerbations. As shown on figure $1 \mathrm{c}$ and $\mathrm{d}$, the patient improved dramatically and durably, with a significant decrease in eosinophil count, precipitins and total and specific IgE levels over time (values after 6 months of LAmB were 370 cells $\mu \mathrm{L}^{-1}$, two lines, $133 \mathrm{IU} \cdot \mathrm{mL}^{-1}$ and $3.05 \mathrm{kU} \cdot \mathrm{L}^{-1}$, respectively, and 6 months after discontinuation of $\mathrm{LAmB}$ were 310 cells $\cdot \mu \mathrm{L}^{-1}$, two lines, $236 \mathrm{IU} \cdot \mathrm{mL}^{-1}$ and $3.28 \mathrm{kU} \cdot \mathrm{L}^{-1}$, respectively). After 2 months of this regimen, prednisolone was stopped and nebulised LAmB continued ( $25 \mathrm{mg}$ once weekly) for 6 months as maintenance therapy. In our case, clinical and radiological improvement accompanied that of biological values, without any side-effects.

Systemic glucocorticoids are the treatment of choice for acute ABPA and exacerbations of ABPA. The Cystic Fibrosis Foundation Consensus Conference on ABPA did not propose a specific treatment plan [1]. Two small, uncontrolled clinical trials evaluated glucocorticoids in ABPA with different glucocorticoid regimens that varied in doses and durations (from 2 to 6 months) [2]. Short-term glucocorticoids reduced the number of exacerbations and improved lung function, but caused long-term sideeffects (diabetes, dyslipidaemia and osteopenia) and exposed patients to the risk of severe infection (ABPA progression to invasive pulmonary aspergillosis).

Systemic antifungal treatments have been recommended in association with glucocorticoids: the objective being the attenuation or even the eradication of the intrabronchial Aspergillus burden, in order to decrease or stop glucocorticoid therapy. Itraconazole is the antifungal agent of choice for this indication, according to the results of two randomised controlled trials 